\title{
Removal of methylene blue dye from aqueous solution using a superabsorbant hydrogel the polyacrylamide: isotherms and kinetic studies
}

\author{
Imane Lebkiri *, Brahim Abbou, Lamya Kadiri, Abdelkarim Ouass, Youness Essaadaoui, Amar \\ Habssaoui, El Housseine Rifi and Ahmed Lebkiri
}

Laboratory of Organic Synthesis and Extraction Processes - Department of Chemistry

University Ibn Tofail, Kenitra - Faculty of Sciences, PO Box. 133, 14000, Kenitra, Morocco

\begin{abstract}
The present work aims the elimination of an organic dye Methylene Blue (MB) by adsorption on the polyacrylamide (PAAM) hydrogel. Several experiments series were then carried out in order to study the influence on the adsorption capacity of certain parameters such as the mass of the adsorbent, the $\mathrm{pH}$, the contact time, the initial dye concentration and the temperature. The maximal capacity is $1620 \mathrm{mg} / \mathrm{g}$ it was obtained at $\mathrm{T}=25^{\circ} \mathrm{C}$, $\mathrm{pH}=6,[\mathrm{BM}]=200 \mathrm{ppm}$ and $0.013 \mathrm{~g}$ of the adsorbent. The adsorption kinetics of the dye on the support is well described by the first-order model. The adsorption isotherms of the adsorbent/adsorbate systems studied are satisfactorily described by the Langmuir mathematical model. On the other hand, the thermodynamic study revealed that adsorption is spontaneous and endothermic.
\end{abstract}

Keywords: Adsorption; hydrogels; dyes; superabsorbent; wastewater.

\section{Introduction}

Synthetic organic dyes are widely used in many industrial sectors such as automotive, chemical area, stationery, and more particularly the textile sector ${ }^{1,2}$ These dyes are evacuated with the effluents that are most of the time directly rejected to the environment without pre-treatment ${ }^{3,4}$. These colored rejects pose an aesthetic problem, but also sanitary because many of dyes are toxic like all dangerous organic compounds ${ }^{5,6}$.

Methylene blue is an organic basic cationic dye that has broad applications including cotton or wools dyeing, paper coloring, temporarily coloring hair, and coating for paper stock. MB has long been used as a model for the adsorption of organic dye from aqueous solutions. Although not actively poisonous, MB can have some harmful effects on human beings ${ }^{7}$. The dye can cause eye burns in humans and animals. It may stimulate the gastrointestinal tract and cause nausea, vomiting, and diarrhea if ingested. It may also cause dyspnea, tachycardia, cyanosis, methemoglobinemia and convulsions if inhaled ${ }^{8}$.

Several treatments were used to reduce the harmful effects of these rejected effluents ${ }^{9}$. Traditional processes such as biological processes give unsatisfactory results ${ }^{10}$ because of the composition of these releases in dyes and toxic materials which are hardly biodegradable. Adsorption remains one of the

*Corresponding author: Imane Lebkiri

Email address: imane.lebkiri@gmail.com

DOI: http://dx.doi.org/10.13171/mjc941911251089il most used and easy to implement techniques ${ }^{11,12}$. The elimination of dyes in aqueous solutions by adsorption on different solid materials, especially on active carbon, has been the subject of different works 13-16.

Nowadays, the development of new adsorbents, which have a large capacity and give significant adsorption rates, has generated a great interest in the treatment of wastewater. Several polymers with different functional groups have attracted attention because of their high adsorption capacities, particularly the regeneration and reuse capabilities ${ }^{17-19}$.

The polyacrylamide is one of the most used polymers for several purposes. It can absorb a large amount of water compared to the other water-absorbing materials. The polyacrylamide is a polymer containing a large number of amide groups. It is considered to be a selective adsorbent to remove pollutants such as dyes and heavy metals from aqueous solutions ${ }^{3,20-22}$.

In this work, we studied the adsorption of a cationic dye methylene blue by a superabsorbent polyacrylamide. The influence of several parameters, such as contact time, the quantity of adsorbent, the concentration of the dye, temperature and $\mathrm{pH}$ on the adsorption capacity and removal efficiency, has been evaluated and discussed for each of these parameters. 
The equilibrium data were analyzed using various adsorption isotherms.

\section{Materials and methods}

\subsection{Adsorbate}

Table 1. Characteristics of methylene blue.

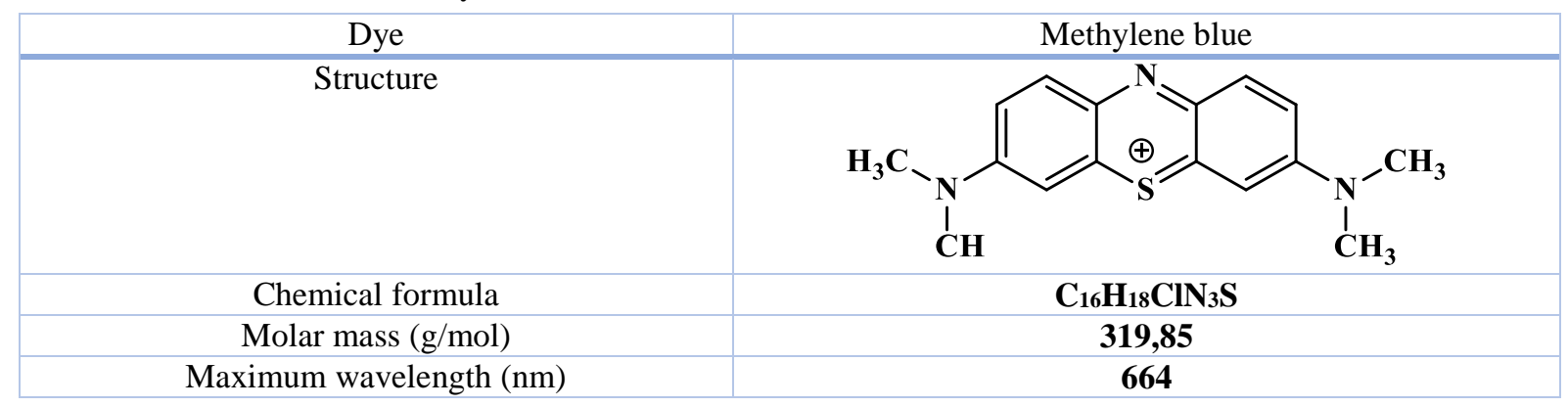

\subsection{Adsorbent}

The material used in this work is the polyacrylamide (PAAM) whose chemical formula is $\left(\left[-\mathrm{C}_{2} \mathrm{H}_{3} \mathrm{CONH}_{2}-\right] \mathrm{n}\right)$. It is superabsorbents that have the form of transparent beads of non-porous surface aspect supplied by Sigma-Aldrich product number: 749222.

\subsection{Adsorption procedure}

The adsorption of MB from aqueous solution onto PAAM was performed using a stirred reactor in the static regime. A suspension containing a mass of adsorbent was mixed by stirring $(100 \mathrm{rpm})$ with a 100 $\mathrm{mL}$ aqueous solution of dye at a known initial
The considered dye in this study is methylene blue (MB) of a very high degree of purity (99\%), was purchased from SOLVACHIM Morocco (reference: 1091), it was used as it was supplied without any prior purification. Its characteristics are summarized in Table 1.

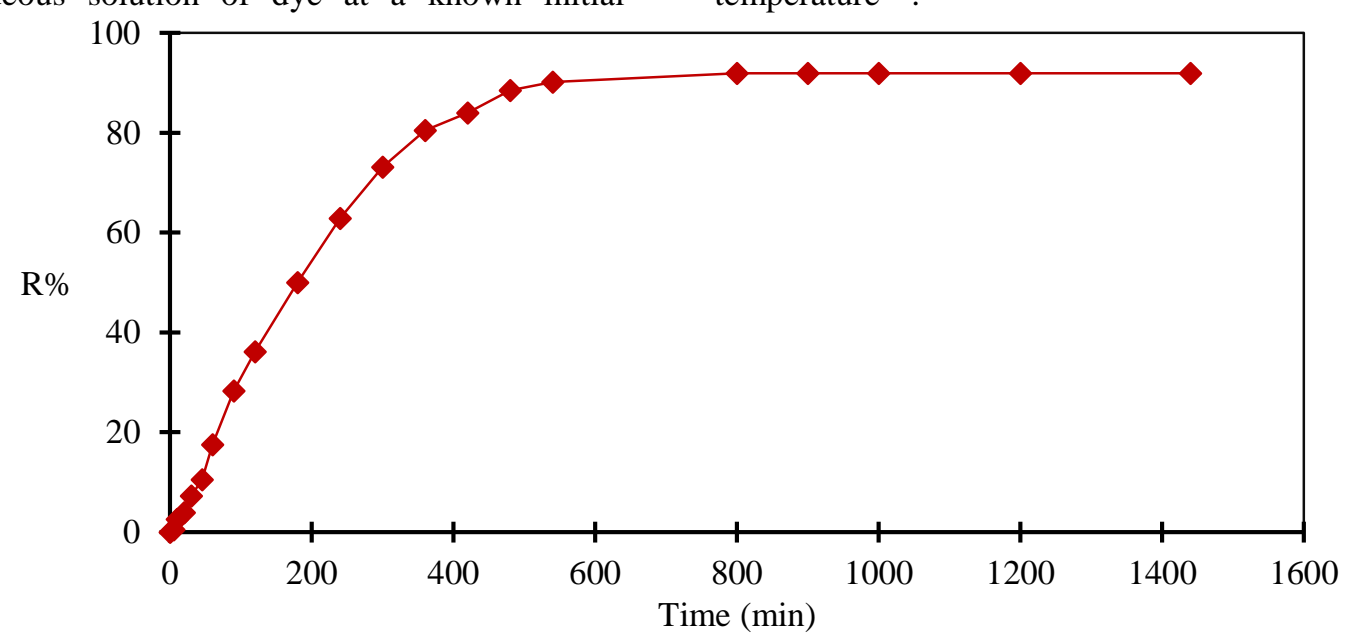

Figure 1. Effect of contact time on the removal of MB dye by PAAM

The obtained data from the adsorption tests were then used to calculate removal efficiency $\mathrm{R} \%$ and the adsorption capacity, Q ( $\left.\mathrm{mg} \mathrm{g}^{-1}\right)$, of the adsorbent, which represents the amount of adsorbed dye per the amount of dry adsorbent using the following equations:

$Q=\frac{C_{i}-C_{f}}{m} * V$

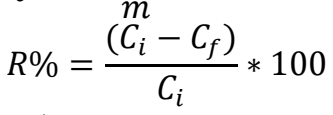

Where concentration in a beaker which was immersed in a bath in thermostatted water keeping constant working temperature. An aliquot of the solution was withdrawn at the pre-determined time intervals. The residual dye concentration in the filtrate was subsequently determined using the MAPADA $\mathrm{V}-1200 \mathrm{UV} / \mathrm{visible}$ spectrophotometer at the wavelength corresponding to the maximum absorbance. The adsorption tests were continued until the equilibrium concentration was reached. The effect of contact time on the amount of dye adsorbed was investigated as a function of the initial concentration of dye, the mass of the adsorbent, $\mathrm{pH}$ and temperature $^{22}$.
- $\quad \mathrm{Q}$ is the adsorbed amount of dye $(\mathrm{mg} / \mathrm{g})$.

- $\mathrm{R} \%$ is the removal efficiency of the dye (\%).

- $\mathrm{C}_{\mathrm{i}}$ and $\mathrm{C}_{\mathrm{f}}$, respectively, the initial dye concentration and in equilibrium $(\mathrm{mg} / \mathrm{L})$.

- $\quad \mathrm{m}$ is the mass of adsorbent $(\mathrm{g})$.

- V the volume of the solution (L). 


\section{Results and Discussion}

\subsection{Parameter influencing the adsorption} 3.1.1. Effect of contact time

The effect of contact time on the rate of the removal of $\mathrm{MB}$ dye was investigated at initial dye concentration 10 ppm, as shown in Figure 1.
The obtained results have shown that the adsorption equilibrium is reached after $540 \mathrm{~min}$ with an efficiency of $90 \%$.

The evolution of $\mathrm{pH}$ and concentration of the dye versus time is shown in Figure 2. There is an increase in the $\mathrm{pH}$ of the solution from 5.5 to 6.14 accompanied by a remarkable decrease of the dye concentration from $9.5 \mathrm{ppm}$ to $0.78 \mathrm{ppm}$. The increase of $\mathrm{pH}$ solution shows that the PAAM balance with the dye solution by consuming $\mathrm{H}^{+}$proton ${ }^{16}$.

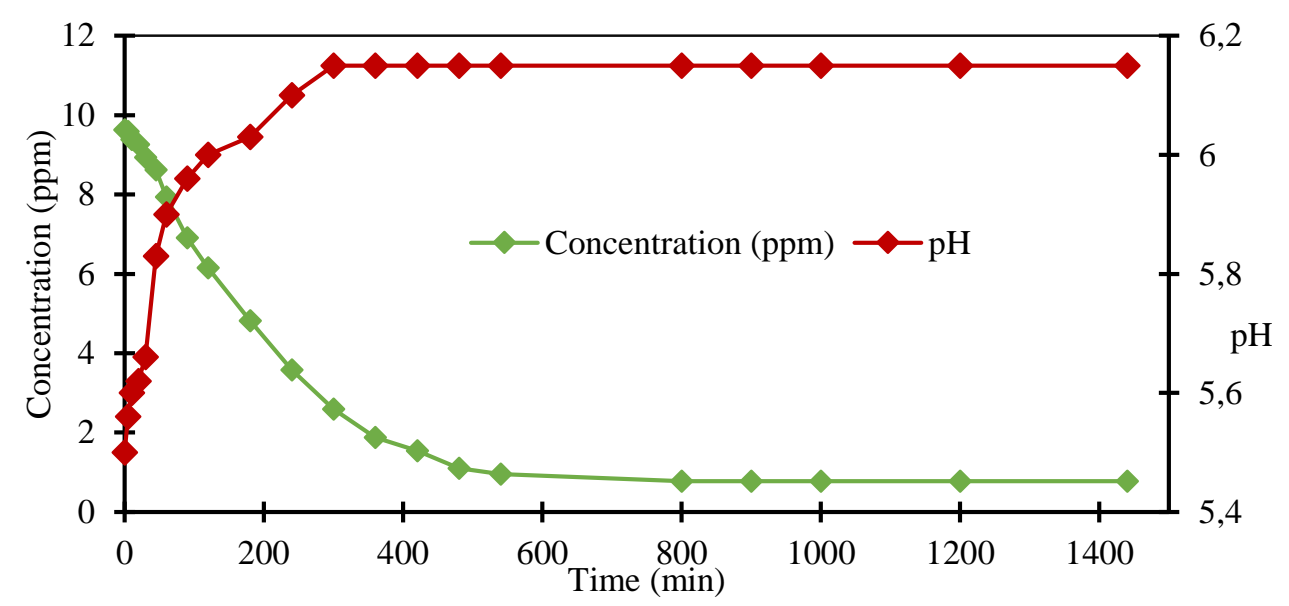

Figure 2. The evolution of $\mathrm{pH}$ and concentration of the dye versus time

\subsubsection{Effect of the adsorbent mass}

The effect of the PAAM mass has been studied for $540 \mathrm{~min}$, by varying the mass of adsorbent (Figure 3) and keeping constant the concentration (10 ppm) of the MB.

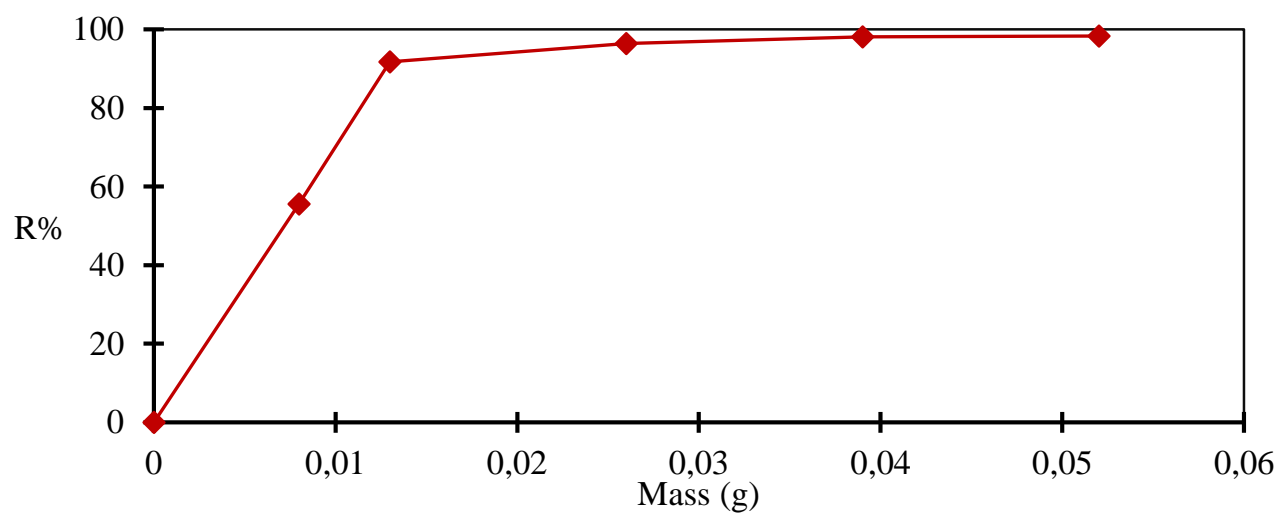

Figure 3. Rate of removal of MB versus the mass of PAAM

The Figure shows that the percentage of elimination of MB increases rapidly from $0.008 \mathrm{~g}$ to $0.013 \mathrm{~g}$ of PAAM. This is due to the increase in specific surface area and the adsorption sites attributed to the increase in adsorbent mass ${ }^{23}$; it appeared that the use of 0.013 $\mathrm{g}$ of PAAM allows eliminating more than $90 \%$ of the MB dye. Beyond $0.013 \mathrm{~g}$, there is no significant change. The removal rate reaches almost $99 \%$ for mass values up to $0.04 \mathrm{~g}$ of PAAM. So, the adsorbent mass was fixed to $0.013 \mathrm{~g}$ for further experiments.

\subsubsection{Effect of $\mathbf{p H}$}

The influence of the $\mathrm{pH}$ on the adsorption of the MB by the PAAM was studied to gain further insight into the adsorption process and that using different solution with different $\mathrm{pH}$ values for $540 \mathrm{~min}$ and the same initial concentration (10 ppm) keeping constant the mass of adsorbent, the stirring speed and room temperature (Figure 4). 


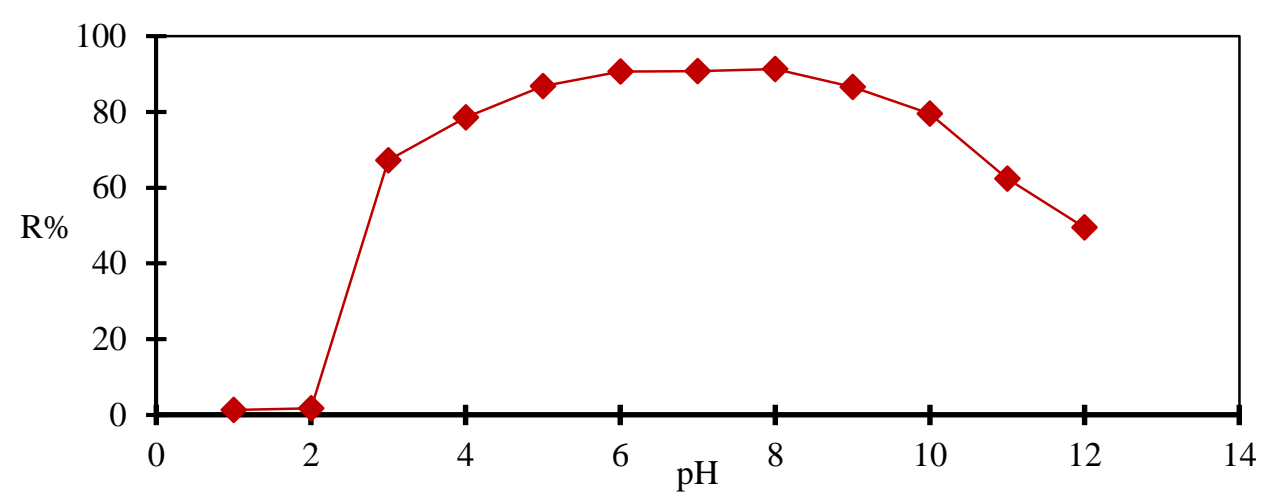

Figure 4. Rate of removal of MB by PAAM versus $\mathrm{pH}$

The results indicate that at low values of $\mathrm{pH}(\mathrm{pH}<2)$ there is no adsorption because There is competition between $\mathrm{MB}^{+}$and the protons to be fixed to PAAM surface, then the dye removal efficiency increases significantly with the increasing $\mathrm{pH}$ value from 2 to 5 , and then slightly increases when the $\mathrm{pH}$ value increased from 5 to 8 reaching its maximum (92\%) and that agreed with to the marge of $\mathrm{pH}$ of wastewater 24,25 . Further increase in the $\mathrm{pH}$ value results in a significant decrease in dye removal efficiency.

\subsubsection{Effect of the temperature}

The influence of temperature on the absorption capacity of the polymer was also studied. The experiments were carried out by adding PAAM to methylene blue solutions with initial concentration 10 ppm at different temperatures $\left(25,35,45\right.$ and $\left.55^{\circ} \mathrm{C}\right)$, and under agitation for $180 \mathrm{~min}$. Figure 5 shows that an increase in temperature from $25^{\circ} \mathrm{C}$. to $55^{\circ} \mathrm{C}$. is accompanied by an increase in the rate of removal of the $\mathrm{MB}$, which goes from $50 \%$ to $83 \%$. This phenomenon suggests that the reaction is endothermic and that the increase in temperature favors the adsorption mechanism. It is well known that temperature plays an important role and can affect several aspects of dye adsorption. In fact, the temperature has a positive influence by increasing the swelling capacity of an adsorbent, the mobility of dye molecules, the number of active sites, and the interaction between the adsorbate and adsorbent. ${ }^{26}$.

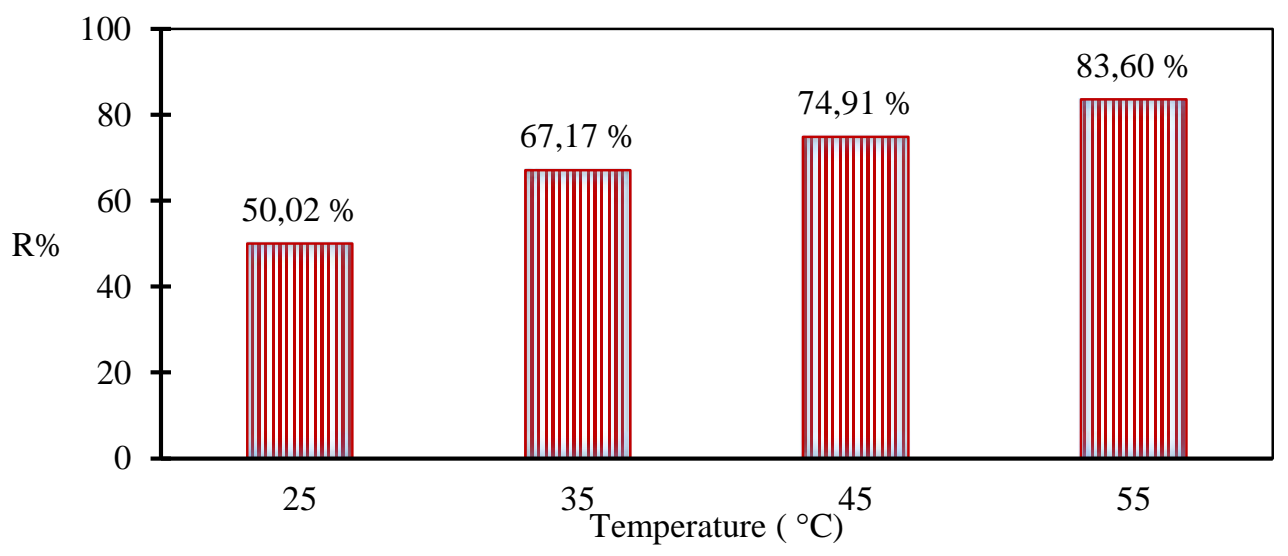

Figure 5. Rate removal of $\mathrm{MB}$ versus the temperature

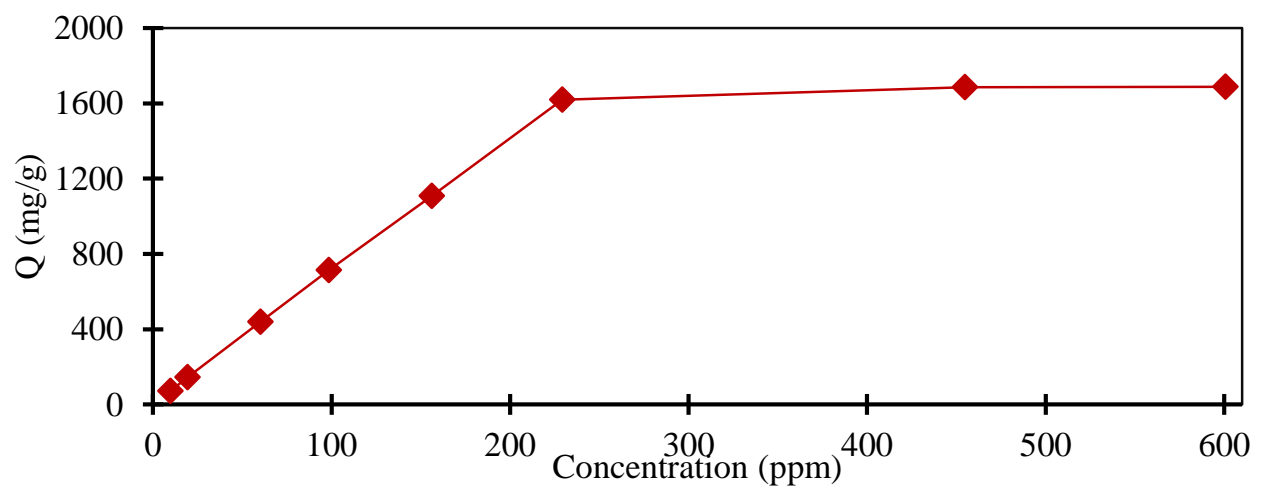

Figure 6. Adsorption capacity versus the initial concentration of the dye 


\subsubsection{Effect of the concentration}

To study the effect of the concentration of the MB on the adsorption capacity, the process has been performed with an initial concentration of the MB between 10 and $600 \mathrm{ppm}$ for $540 \mathrm{~min}$, while maintaining the other four parameters constant (Figure 6).

The results show that the adsorption capacity of PAAM increases with the increase in the initial concentration of MB dye. Beyond a concentration of $230 \mathrm{ppm}$, there is a plateau due to the saturation of the active sites of the adsorbent in the presence of high content of dye. The increase in concentration induces the elevation of the driving force of the concentration gradient, thus the increase of diffusion of the dye molecules in solution across the surface of the adsorbent ${ }^{27}$. The maximum load of PAAM in MB expressed in $\mathrm{mg}$ of fixed dye per gram of the support is of the order of $1620 \mathrm{mg} / \mathrm{g}$.

\subsection{Adsorption kinetics and isotherms}

\subsubsection{Adsorption Isotherms}

The data of the effect of the concentration on the adsorption of MB by the PAAM are treated according to linear equations of Langmuir and Freundlich. The purpose of this linearization is to be able to verify the model according to which the adsorption takes place and to deduce the maximum adsorbed quantities as well as the affinity of the adsorbate for the adsorbent.

\subsubsection{Langmuir isotherm}

The linear form of the Langmuir isotherm is given by the following equation ${ }^{28}$ :

$\frac{C_{e}}{Q_{e}}=\frac{1}{K_{L} Q_{\max }}+\frac{C_{e}}{Q_{\max }}$

With:

- $\mathrm{C}_{\mathrm{e}}(\mathrm{mg} / \mathrm{L})$ is the concentration in equilibrium,

- $\mathrm{Q}_{\mathrm{e}}(\mathrm{mg} / \mathrm{g})$ is the quantity adsorbed at equilibrium,

- $\quad \mathrm{Q}_{\max }(\mathrm{mg} / \mathrm{g})$ is the maximum quantity adsorbed,

- $\quad \mathrm{K}_{\mathrm{L}}(\mathrm{L} / \mathrm{mg})$ is the constant of Langmuir.

The dimensional parameter of Hall $\mathrm{R}_{\mathrm{L}}$ can verify the favorability of the isotherm of Langmuir which comes under the following form:

$$
R_{L}=\frac{1}{1+K_{L} C_{0}}
$$

With $\mathrm{C}_{0}$ the initial concentration in $\mathrm{mg} / \mathrm{L}$.

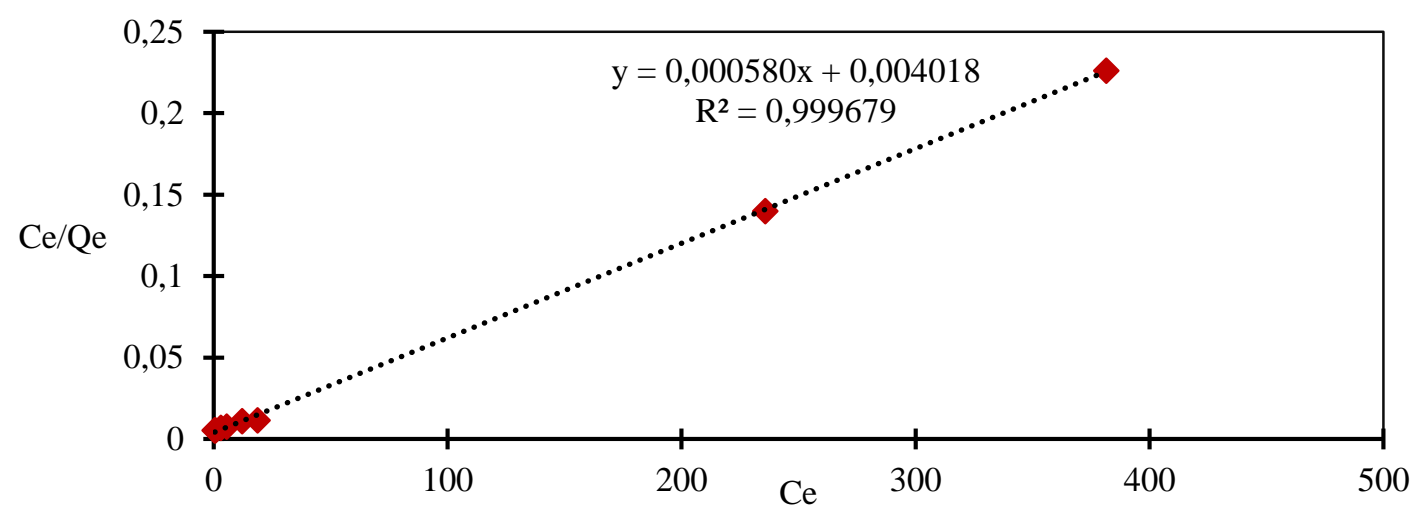

Figure 7. The linear form of the model of Langmuir of the MB on the PAAM

A straight line was obtained when $\mathrm{C}_{\mathrm{e}} / \mathrm{Q}_{\mathrm{e}}$ was plotted against $\mathrm{C}_{\mathrm{e}}$ (Figure 7), and $\mathrm{Q}_{\max }$ and $\mathrm{K}_{\mathrm{L}}$ could be

evaluated from the slope and intercept (Table 2)

Table 2. Parameters of adsorption of the MB on the PAAM according to Langmuir model

\begin{tabular}{|c|c|c|c|c|c|}
\hline $\mathrm{Q}_{\text {max }, \mathrm{th}}(\mathrm{mg} / \mathrm{g})$ & $\mathrm{Q}_{\max , \mathrm{ex}}(\mathrm{mg} / \mathrm{g})$ & $\mathrm{DR}$ & $\mathrm{K}_{\mathrm{L}}(\mathrm{L} / \mathrm{mg})$ & $\mathrm{R}_{\mathrm{L}}$ & $\mathrm{R}^{2}$ \\
\hline $\mathbf{1 7 2 1}, \mathbf{1 7}$ & 1686.9 & $1,9 \%$ & 0.15 & $0.408-0.0109$ & 0.999 \\
\hline
\end{tabular}

The maximum adsorbed quantity obtained by the Langmuir model $1721.17 \mathrm{mg} / \mathrm{g}$ is very close to that obtained experimentally $1686.9 \mathrm{mg} / \mathrm{g}$, the coefficient of determination $\mathrm{R}^{2}=0.999$ demonstrate that the adsorption of $\mathrm{MB}$ onto PAAM follows the Langmuir's model and the constant of Hall $\mathrm{R}_{\mathrm{L}}<1$ implying that the adsorption of $\mathrm{MB}$ on PAAM is favourable ${ }^{29}$.

\subsubsection{Freundlich isotherm}

The linear form of the Freundlich isotherm is given by the following equation ${ }^{30}$ :

$\ln Q_{e}=\ln K_{f}+\frac{1}{n} \ln C_{e}$

With:

- $\quad \mathrm{K}_{\mathrm{f}}, \mathrm{n}$ : Empirical constants of Freundlich 


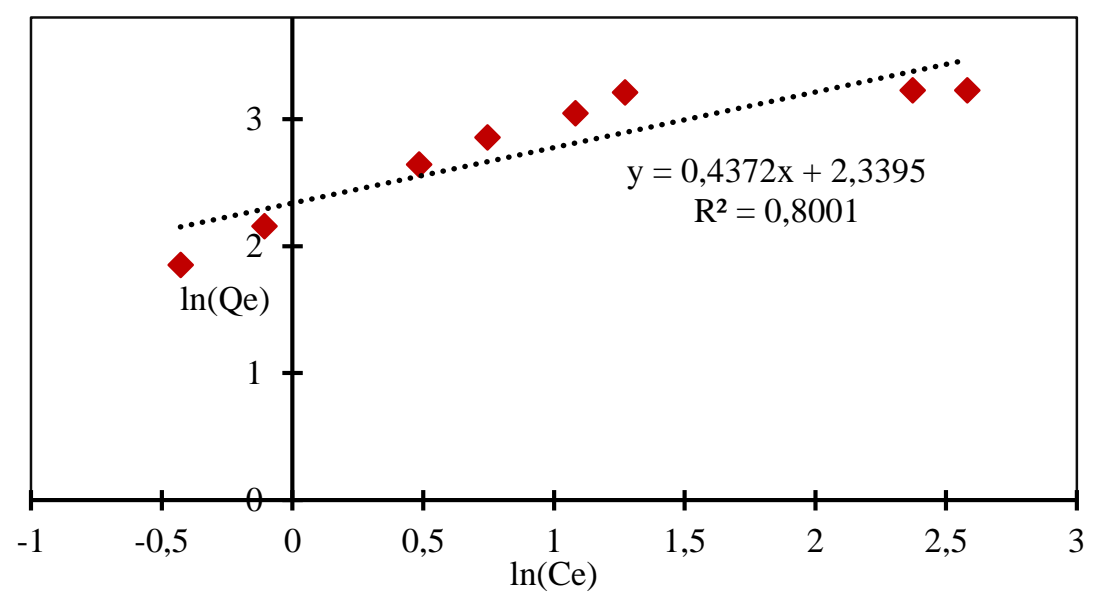

Figure 8. Freundlich isotherm applied to adsorption of MB by PAAM.

A straight line was obtained when $\operatorname{Ln}\left(\mathrm{Q}_{\mathrm{e}}\right)$ was plotted against $\operatorname{Ln}\left(\mathrm{C}_{\mathrm{e}}\right)$ (Figure 8 ) and $\mathrm{n}$ and $\mathrm{K}_{\mathrm{f}}$ could be

Table 3. Freundlich isotherm constants for adsorption of MB by PAAM.

\begin{tabular}{|c|c|c|}
\hline $1 / \mathrm{n}$ & $\mathrm{K}_{\mathrm{f}}(\mathrm{mg} / \mathrm{g})(\mathrm{L} / \mathrm{mg})^{1 / \mathrm{n}}$ & $\mathrm{R}^{2}$ \\
\hline $\mathbf{0 . 4 3 7 2}$ & 10.37 & 0.8001 \\
\hline
\end{tabular}

Values of $\mathrm{n}>1$ represent favorable adsorption conditions. According to the coefficients of determination, the Langmuir model fits better than the Freundlich model.

\subsubsection{Kinetic studies}

The adsorption kinetics represent the evolution of a parameter corresponding to the adsorption process with time. It provides information on the adsorption mechanism and the mode of transfer of solutes from the liquid phase to the solid phase. Like the adsorption equilibrium, the adsorption kinetics of a material can be modeled. For this purpose, the literature reports some models, such as the Lagergren model (firstorder model), the kinetic model of order two, the model of intraparticle diffusion ${ }^{31,32}$. We used in this study, first and second-order kinetic laws.

\subsubsection{First-order model}

The linear form of this law is given by ${ }^{33}$ :

$\ln \left(Q_{e}-Q(t)\right)=\ln Q_{e}-K_{1} t$

With $\mathrm{K}_{1}$ first-order rate constant $\left(\mathrm{min}^{-1}\right)$, it can be determined by representing $\ln \left(\mathrm{Q}_{\mathrm{e}}-\mathrm{Q}(\mathrm{t})\right)$ according to time t (Figure 9).

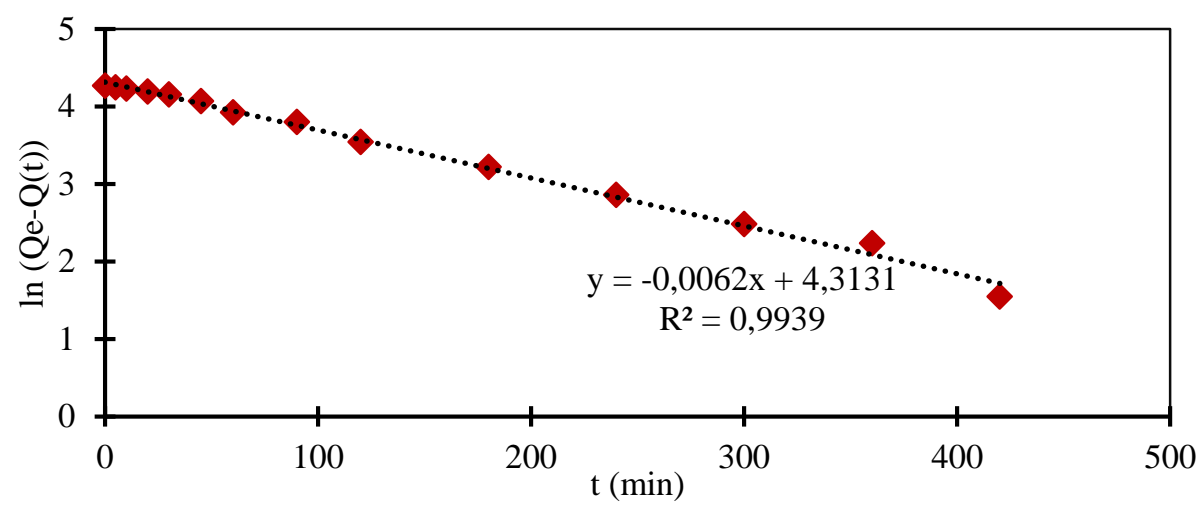

Figure 9. Pseudo-first-order kinetic model applied to adsorption of the MB on the PAAM.

The value of the adsorbed quantity $\mathrm{Q}_{\mathrm{e}}$, the pseudofirst-order constant $\mathrm{K}_{1}$ and the regression coefficient

$\mathrm{R}^{2}$ are given in Table 4 .

Table 4. Kinetic constants of the pseudo-first-order model

\begin{tabular}{|c|c|c|}
\hline $\mathrm{Q}_{\mathrm{e}}(\mathrm{mg} / \mathrm{g})$ & $\mathrm{K}_{1}\left(\mathrm{~min}^{-1}\right)$ & $\mathrm{R}^{2}$ \\
\hline 74.67 & $\mathbf{0 . 0 0 6 2}$ & $\mathbf{0 . 9 9 3 9}$ \\
\hline
\end{tabular}


From Table 4, the calculated value of the adsorbed amount $\mathrm{Q}_{\mathrm{e}}$ agrees with the experimental $\mathrm{Q}_{\mathrm{e}}$ and the value of the correlation coefficient approaches the unity $\left(\mathrm{R}^{2}=0.9939\right)$. These results illustrate that the adsorption of MB onto PAAM fits the pseudo-firstorder model.

\subsubsection{Pseudo-second-order model}

This model allows characterizing the kinetics of adsorption, taking into account both the case of quick fixation of solutes on the most responsive sites and slow fixated on the sites for low energy ${ }^{34}$. The linear form of this model is written ${ }^{35}$ :

$\frac{t}{Q(t)}=\frac{1}{K_{2} Q_{e}^{2}}+\frac{1}{Q_{e}} t$

Where $\mathrm{K}_{2}$ of the second-order ( $\mathrm{g} / \mathrm{mg}$.min) adsorption rate constant determined by tracing $t / Q$ versus $t$ (Figure 10).

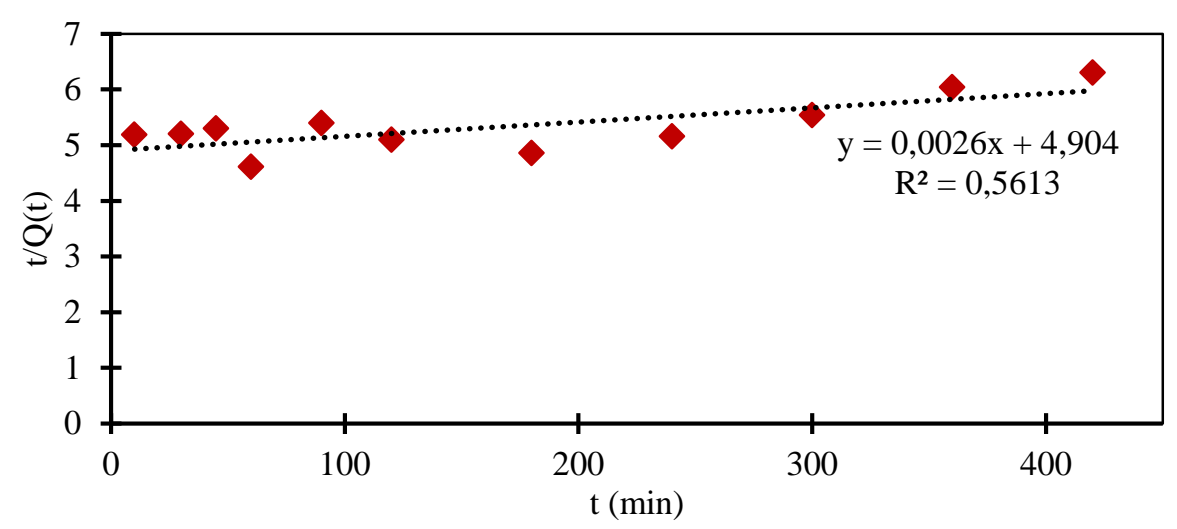

Figure 10. Pseudo-second-order' kinetic model applied to adsorption of the MB on the PAAM.

Figure 10 illustrates the results of the application of the pseudo-second-order kinetic model relating to the adsorption of the MB dye on PAAM. The calculated values of the adsorbed quantities $\mathrm{Q}_{\mathrm{e}}$, the pseudosecond-order constants $\mathrm{K}_{2}$ and the regression coefficients $\mathrm{R}^{2}$ are given in Table 5 .

Table 5. Kinetic constants of the pseudo-second order model

\begin{tabular}{|c|c|c|}
\hline $\mathrm{Q}_{\mathrm{e}}(\mathrm{mg} / \mathrm{g})$ & $\mathrm{K}_{2} 10^{-6}(\mathrm{~g} / \mathrm{mg} \cdot \mathrm{min})$ & $\mathrm{R}^{2}$ \\
\hline 384.61 & $\mathbf{1 . 3 7}$ & $\mathbf{0 . 6 6 8 3}$ \\
\hline
\end{tabular}

According to Table 5, the experimental $\mathrm{Q}_{\mathrm{e}}$ is not in agreement with calculated $\mathrm{Q}_{\mathrm{e}}$, and the coefficients of determination $\mathrm{R}^{2}$ is low. Accordingly, the adsorption of MB onto PAAM does not follow the pseudosecond-order kinetic model.

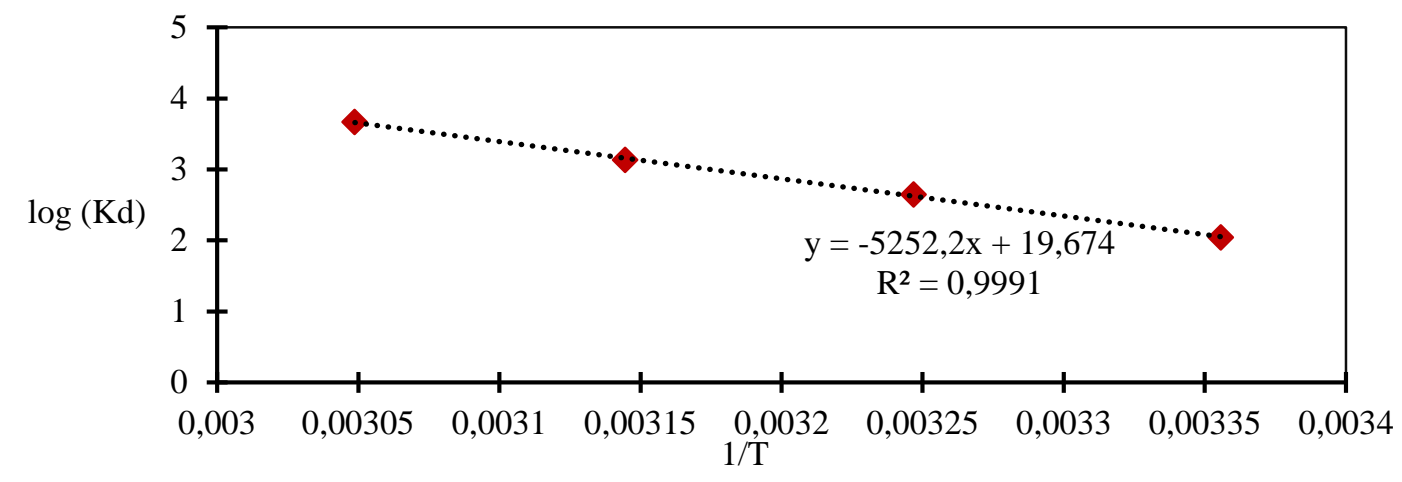

Figure 11. Van'tHoff curve corresponding to the adsorption of MB by PAAM

\subsection{Thermodynamic parameters}

The thermodynamic parameters of MB adsorption by PAAM were determined at different temperatures with an initial dye concentration of $10 \mathrm{mg} / \mathrm{L}$ using the following equations ${ }^{36}$ :

$$
\begin{aligned}
& \Delta G_{a d s}=\Delta H_{a d s}-T \Delta S_{a d s} \\
& \Delta G^{0}=-R T \ln K_{c}
\end{aligned}
$$

$K_{d}=\frac{Q_{e}}{C_{e}}$

Where

- $\quad \mathrm{T}$ the temperature in Kelvin,

- $\mathrm{R}\left(8.314 \times 10^{-3} \mathrm{KJ} \cdot \mathrm{mol}^{-1} \cdot \mathrm{K}^{-1}\right)$ is the ideal gas constant,

- $\quad K_{d}$ is the distribution coefficient,

- $\mathrm{C}_{\mathrm{e}}(\mathrm{mg} / \mathrm{L})$ is the concentration in equilibrium,

- $\mathrm{Q}_{\mathrm{e}}(\mathrm{mg} / \mathrm{g})$ is the quantity adsorbed at equilibrium, 
$\Delta \mathrm{H}^{\circ}$ and $\Delta \mathrm{S}^{\mathrm{o}}$ were calculated from the intercept and slope of the plot of $\ln \left(\mathrm{K}_{\mathrm{d}}\right)$ versus $1 / \mathrm{T}$ (Figure 11) using de Van't Hoff equation:

$$
\ln K_{d}=\left(\frac{\Delta S^{0}}{R}\right)-\left(\frac{\Delta H^{0}}{R}\right) \frac{1}{T}
$$

The thermodynamic parameters were listed in Table 6.

Table 6. Thermodynamic parameters of adsorption of MB on PAAM.

\begin{tabular}{|c|c|c|c|c|}
\hline $\mathrm{T}(\mathrm{K})$ & $\Delta \boldsymbol{H}^{\boldsymbol{o}}(\mathrm{KJ} / \mathrm{mol})$ & $\Delta \boldsymbol{S}^{\boldsymbol{o}}(\mathrm{J} /(\mathrm{K} . \mathrm{mol}))$ & $\Delta \boldsymbol{G}^{\boldsymbol{o}}(\mathrm{KJ} / \mathrm{mol})$ & $\mathrm{R}^{2}$ \\
\hline $\mathbf{2 9 8}$ & 43.66 & 163.56 & -4.94 & 0,9991 \\
\hline $\mathbf{3 0 8}$ & & & -6.62 & \\
\hline $\mathbf{3 1 8}$ & & & -8.10 & \\
\hline 332 & & & -9.78 & \\
\hline
\end{tabular}

The positive value of $\Delta \mathrm{H}^{\mathrm{o}}$ confirms the endothermic nature of $\mathrm{MB}$ adsorption on PAAM. And the negative value of $\Delta \mathrm{G}^{\mathrm{o}}$ reveals the spontaneity of the adsorption

\section{Comparison with other adsorbents}

It is found that the adsorption amount of PAAM among the highest capacities of hydrogels. process. The positive value of $\Delta \mathrm{S}^{\mathrm{o}}$ demonstrates the increased randomness at the solid--solute interface ${ }^{37}$.

Table 7 has shown various adsorbents that have been studied previously for the removal of methylene blue.

Table 7. Comparative study of the extraction of MB by different materials.

\begin{tabular}{|l|c|c|}
\hline \multicolumn{1}{|c|}{ Adsorbent } & Adsorption capacity (mg/g) & Reference \\
\hline $\begin{array}{l}\text { Superabsorbent hydrogel: the } \\
\text { polysaccharide }\end{array}$ & 48 & 38 \\
\hline $\begin{array}{l}\text { TiO 2 loaded 2D montmorillonite } \\
\text { (2DMMT ) -chitosan -poly (acrylic acid) } \\
\text { hydrogel }\end{array}$ & 250 & 39 \\
\hline $\begin{array}{l}\text { sodium humate/poly(acrylamide- } \\
\text { comethacrylic acid)/kaolin semi- } \\
\text { interpenetrating polymer network hybrid } \\
\text { hydrogel }\end{array}$ & 833.33 & 40 \\
\hline The polyacrylamide & & \\
\hline Xylan-based superabsorbant hydrogel & 1620 & Present work \\
\hline
\end{tabular}

\section{Conclusion}

This study has highlighted the effectiveness of the polyacrylamide in removing the methylene blue dye from aqueous solution. The influence of the parameters related to the operating conditions such as the contact time, the amount of adsorbent, the $\mathrm{pH}$, the initial concentration of the dye and the temperature was examined for each of these parameters. The effect of the contact time shows that the equilibrium is established after 540 minutes and that the adsorption mechanism can be described by pseudofirst-order kinetics. The plot of the adsorption isotherms shows that the Langmuir model fully represents the adsorption of methylene blue on the polyacrylamide with a maximum adsorption capacity of about $1686.9 \mathrm{mg} / \mathrm{g}$. The thermodynamic study reveals that the increase in temperature favors the adsorption of MB. In addition, the adsorption process is endothermic and spontaneous.

\section{References}

1- S. Barreca, S. Orecchio, A. Pace. The effect of montmorillonite clay in alginate gel beads for polychlorinated biphenyl adsorption: Isothermal and kinetic studies. Appl. Clay Sci., 2014, 99, 220-228.

2- L. Kadiri, A. Ouass, Y. Essaadaoui, E.H. Rifi, A. Lebkiri, Coriandrum Sativum seeds as a lowcost green biosorbent for methylene blue dye removal from aqueous solution: spectroscopic kinetic and thermodynamic studies, Mediterr. J. Chem., 2018, 7 (3), 204.

3- Q. Li, Y. Zhao, L. Wang, W. Aiqin. Adsorption characteristics of methylene blue onto the $\mathrm{N}$-succinyl-chitosan-g-polyacrylamide/attapulgite composite. Korean J. Chem. Eng., 2011, 28 (8), 1658-1664.

4- A. Ahmad, M. Rafatullah, O. Sulaiman, M.H. Ibrahim, R. Hashim. Scavenging behaviour of meranti sawdust in the removal of methylene blue from aqueous solution. J. Hazard. Mater., 2009, 170 (1), 357-365.

5- N. Daneshvar, D. Salari, A.R. Khataee, Photocatalytic degradation of azo dye acid red 14 in water: investigation of the effect of operational parameters, J. Photochem. Photobiol. Chem., 2003, 157 (1), 111-116. 
6- W. Zhang, H. Yan, H. Li, et al. Removal of dyes from aqueous solutions by straw-based adsorbents: Batch and column studies. Chem. Eng. J., 2011, 168 (3), 1120-1127.

7- N. Wang, J. Chen, J. Wang, J. Feng, W. Yan, Removal of methylene blue by Polyaniline/TiO2 hydrate: Adsorption kinetic, isotherm and mechanism studies, Powder Technol., 2019, 347, 93-102.

8- Momina, M. Rafatullah, S. Ismail, A. Ahmad. Optimization Study for the Desorption of Methylene Blue Dye from Clay Based Adsorbent Coating, Water 2019, 11 (6), 1304.

9- S. S., I. Abustan, I. Dahlan, et al., Treatment of Dye Wastewater Using Granular Activated Carbon and Zeolite Filter. Mod. Appl. Sci., 2012, $6(2)$.

10- Y. Essaadaoui, A. Lebkiri, E.H. Rifi, L. Kadiri, A. Ouass, Adsorption of cobalt from aqueous solutions onto Bark of Eucalyptus. Mediterr. J. Chem., 2018, 7 (2), 145-155.

11- D. Sun, X. Zhang, Y. Wu, X. Liu. Adsorption of anionic dyes from aqueous solution on fly ash, J. Hazard. Mater., 2010, 181 (1), 335-342.

12-I.A.W. Tan, A.L. Ahmad, B.H. Hameed, Adsorption of basic dye using activated carbon prepared from oil palm shell: batch and fixed bed studies, Desalination, 2008, 225 (1), 13-28.

13-K.K.H. Choy, G. McKay, J.F. Porter, Sorption of acid dyes from effluents using activated carbon. Resour. Conserv. Recycl., 1999, 27 (1), 57-71.

14-P.C.C. Faria, J.J.M. Órfão, M.F.R. Pereira, Adsorption of anionic and cationic dyes on activated carbons with different surface chemistries. Water Res. 2004, 38 (8), 2043-2052.

15- V. Gómez, M.S. Larrechi, M.P. Callao. Kinetic and adsorption study of acid dye removal using activated carbon, Chemosphere, 2007, 69 (7), 1151-1158.

16- L. Kadiri, A. Lebkiri, E.H. Rifi, et al. Kinetic studies of adsorption of $\mathrm{Cu}$ (II) from aqueous solution by coriander seeds (Coriandrum Sativum), E3S Web Conf., 2018, 37, 02005.

17- B.F. Senkal, E. Yavuz, Preparation of poly(vinyl pyrrolidone) grafted sulfonamide based polystyrene resin and its use for the removal of dye from water

https://onlinelibrary.wiley.com/doi/abs/10.1002/p at.837 (accessed Aug 25, 2019).

18-A. Ouass, Y. Essaadaoui, L. Kadiri, et al., Adsorption of $\mathrm{Cr}$ (III) from aqueous solution by two forms of a superabsorbant polymer : parametric study and effect of activation mode. In E3S Web of Conferences; EDP Sciences, 2018, Vol. 37, p 02001.

19-A. Ouass, L. Kadiri, Y. Essaadaoui, et al., Removal of trivalent chromium ions from aqueous solutions by Sodium polyacrylate beads. Mediterr. J. Chem., 2018, 7 (2), 125-134.

20- Y. Zhao, Y. Chen, M. Li, et al., Adsorption of $\mathrm{Hg} 2+$ from aqueous solution onto polyacrylamide/attapulgite. J. Hazard. Mater. 2009, 171 (1), 640-646.

21 - T.S. Anirudhan, P.S. Suchithra. Adsorption characteristics of humic acid-immobilized amine modified polyacrylamide/bentonite composite for cationic dyes in aqueous solutions. J. Environ. Sci., 2009, 21 (7), 884-891.

22- J. Rahchamani, H.Z. Mousavi, M. Behzad. Adsorption of methyl violet from aqueous solution by polyacrylamide as an adsorbent: Isotherm and kinetic studies, Desalination, 2011 , 267 (2-3), 256-260.

23- R. Liu, B. Zhang, D. Mei, H. Zhang, J. Liu. Adsorption of methyl violet from aqueous solution by halloysite nanotubes. Desalination, 2011, 268 (1), 111-116.

24-D. Belghyti, Y. El Guamri, G. Ztit, et al. Caractérisation physico-chimique des eaux usées d'abattoir en vue de la mise en oeuvre d'un traitement adéquat : cas de Kénitra au Maroc, Afr. Sci. Rev. Int. Sci. Technol., 2009, 5 (2).

25- M. Boutayeb, A. Bouzidi, M. Fekhaoui. Etude de la qualité physico-chimique des eaux usées brutes de cinq villes de la région de la ChaouiaOuardigha (Maroc), Bull. L'institut Sci. Rabat Sect. Sci. Vie 2012, 34 (2), 145-150.

26- M. Constantin, I. Asmarandei, V. Harabagiu, et al. Removal of anionic dyes from aqueous solutions by an ion-exchanger based on pullulan microspheres. Carbohydr. Polym., 2013, 91 (1), 74-84.

27- F. Deniz, S.D. Saygideger. Investigation of adsorption characteristics of Basic Red 46 onto gypsum: Equilibrium, kinetic and thermodynamic studies, Desalination, 2010, 262 (1), 161-165.

28- I. Langmuir. THE CONSTITUTION AND FUNDAMENTAL PROPERTIES OF SOLIDS AND LIQUIDS. PART I. SOLIDS, J. Am. Chem. Soc., 1916, 38 (11), 2221-2295.

29- A. Ouass, I. Ismi, H. Elaidi, et al. Mathematical Modeling of The Adsorption Of Trivalent Chromium By The Sodium Polyacrylate Beads, J. Mater. Environ. Sci., 2017, 8, 3448-3456.

30- H. Freundlich. Über die Adsorption in Lösungen, Z. Für Phys. Chem., 1907, 57U (1).

31- L. Kadiri, M. Galai, M. Ouakki, et al., Coriandrum Sativum. L Seeds Extract as a Novel Green Corrosion Inhibitor for Mild Steel in 1.0 M Hydrochloric and 0.5 M Sulfuric Solutions. Anal. Bioanal. Chem., 2018, 10, 249-268.

32-Y. Essaadaoui, M. Galai, M. Ouakki, et al., Study of the anticorrosive action of eucalyptus camaldulensis extract in case of mild steel in 1.0 M HCl, J. Chem. Technol. Metall., 2019, 81 (7).

33- M. Doğan, M. Alkan, Ö. Demirbaş, Y. Özdemir, C. Özmetin, Adsorption kinetics of maxilon blue GRL onto sepiolite from aqueous solutions. Chem. Eng. J., 2006, 124 (1), 89-101.

34- K. Elass, A. Laachach, A. Alaoui, M. Azzi, Removal of methylene blue from aqueous solution using ghassoul a low-cost adsorbent, 2010 
35- Y. Essaadaoui, A. Lebkiri, E. Rifi, L. Kadiri, A. Ouass, Adsorption of lead by modified Eucalyptus camaldulensis barks : equilibrium, kinetic and thermodynamic studies. Desalination Water Treat., 2018, 111, 267-277.

36- Y. Yao, F. Xu, M. Chen, Z. Xu, Z. Zhu. Adsorption behavior of methylene blue on carbon nanotubes. Bioresour. Technol., 2010, 101 (9), 3040-3046.

37- N. Nasuha, B.H. Hameed, Adsorption of methylene blue from aqueous solution onto $\mathrm{NaOH}$-modified rejected tea. Chem. Eng. J., 2011, 166 (2), 783-786.

38- A.T. Paulino, M.R. Guilherme, A.V. Reis, et al., Removal of methylene blue dye from an aqueous media using superabsorbent hydrogel supported on modified polysaccharide. J. Colloid Interface Sci., 2006, 301 (1), 55-62.
39- W. Wang, H. Bai, Y. Zhao, et al., Synthesis of chitosan cross-linked 3D network-structured hydrogel for methylene blue removal. Int. J. Biol. Macromol., 2019, 141, 98-107.

40- E. Yilmaz, G. Guzel Kaya, H. Deveci. Removal of methylene blue dye from aqueous solution by semi-interpenetrating polymer network hybrid hydrogel: Optimization through Taguchi method. J. Polym. Sci. Part Polym. Chem., 2019, 57 (10), 1070-1078.

41- Y. Lin, G. Fang, Y. Deng, K. Shen, C. Huang, T. Wu, A pH-sensitive Xylan-based Superabsorbant Hydrogel for the removal of Methylene Blue from water, BioResources, 2019, 14(3), 5573-5585. 